\title{
Avaliação da eficiência da utilização do oxigênio dissolvido como principal indicador da qualidade das águas superficiais da Bacia do Córrego Bom Jardim, Brasilândia/MS.
}

\author{
André Luiz Pinto ${ }^{1}$ \\ Gustavo Henrique de Oliveira ${ }^{2}$ \\ Gabrielle Alberta Pereira ${ }^{3}$ \\ ${ }^{1}$ Professor Dr. Associado II da UFMS/CPTL - Departamento de Ciências Humanas \\ Caixa Postal 210 - 79620-080 - Três Lagoas - MS, Brasil \\ andreluiz@cplt.ufms.br \\ ${ }^{2}$ Discente do Curso de Geografia Bacharelado da UFMS/CPTL - Bolsista de Iniciação \\ Científica - CNPq - PIBIC \\ Rua Francisco Peres Marques, 320 - 16202-030 - Birigui - SP, Brasil \\ henriqueguo@hotmail.com \\ ${ }^{3}$ Discente do Curso de Geografia Bacharelado da UFMS/CPTL \\ Viela Particular, 2.423 - 79600-000 - Três Lagoas - MS, Brasil \\ gabialberta@gmail.com
}

\begin{abstract}
The present work aims to evaluate the quality of surface water in the basin of the Bom Jardim stream, in the municipality of Brasilândia / MS, we used the dissolved oxygen as the main indicator of quality and supporting parameters of $\mathrm{pH}$, turbidity and electrical conductivity. For the analysis were chosen eight stations along the main channel and the mouth of its tributaries monitored in the summers of 2008 and 2009. And evaluated the quality before classes framing CONAMA Resolution 357/2005. The ease of obtaining measurements of dissolved oxygen in the field, its low cost and efficiency demonstrated its feasibility for placement in classes of CONAMA. Considering that, the campaigns conducted by municipal and state agencies to assess the condition of the rivers that cut through their territories are expensive and therefore, are not performed often with the use of OD these can be made with greater consistency.
\end{abstract}

Palavras-chave: Quality of the superficial waters, Oxygen dissolved, Framing of basin, Qualidade das águas superficiais. Oxigênio dissolvido. Enquadramento de bacia. 


\section{Introdução}

No Brasil, como em todo o mundo, emergem a preocupação com o meio ambiente devido inúmeras modificações feitas na natureza.

Somos a cada passo advertidos de que não podemos dominar a natureza como um conquistador domina um povo estrangeiro, como alguém situado fora da natureza; nós lhe pertencemos, com a nossa carne, nosso sangue, nosso cérebro; estamos no meio dela; e todo o nosso domínio sobre ela consiste na vantagem que levamos sobre os demais seres de poder chegar a conhecer suas leis e aplicá-las corretamente. É através da compreensão das leis da natureza que se pode tratar das questões ambientais, e a natureza deve ser vista como um sistema maior formado por outros subsistemas integrados (ENGELS, 1976 apud CASSETI, 1994, p. 29).

Devido ao uso, ocupação e manejo predatório da terra empregado a mais de um século na bacia do Córrego Bom Jardim, localizada no município de Brasilândia/MS, agravado pelos assentamentos desenvolvidos pela Companhia Energética de São Paulo - CESP, que não tiveram rigorosa fiscalização do cumprimento da legislação ambiental, esta se encontra submetida a acelerado ciclo erosivo, pondo em risco a sede do município, a cidade de Brasilândia, onde grandes ravinamentos e boçorocamentos avançam sobre vias públicas e edificações prediais domiciliares e públicas. Além de assorear o lago da Usina Hidrelétrica de Porto Primavera, no rio Paraná.

Sendo a bacia hidrográfica um sistema biofísico e socioeconômico, integrado e interdependente, contemplando atividades agrícolas, industriais, comunicações, serviços, facilidades, recreacionais, formações vegetais, nascentes, córregos, riachos, lagoas e represas, enfim, todos os habitats e unidades da paisagem. Seus limites são estabelecidos topograficamente pela linha que une os pontos de maior altitude e que definem os divisores de água entre uma bacia e outra adjacente. Uma característica importante é o fato de ser uma unidade funcional, com processos e interações ecológicas passíveis de serem estruturalmente caracterizados, quantificados e matematicamente modelados (ESPINDOLA, 2000).

Para Rocha et. al (2000) qualquer tipo de uso do solo na bacia hidrográfica interfere no ciclo hidrológico, não importando o grau com que esse tipo de uso utiliza ou dependa diretamente da água.

Portanto o uso, ocupação e manejo da terra influenciam na dinâmica do escoamento superficial/subterrâneo, propiciando graus diferenciados de resistência às ações dos agentes externos e processos que modelam a sua morfologia, e consecutivamente os transportes de materiais que interferem na qualidade da água desse manancial.

O oxigênio dissolvido é de fundamental importância na manutenção da vida aquática e da qualidade da água. Tchobanoglous e Schroeder (1985) afirmam que, devido à sua importância, o oxigênio dissolvido é amplamente utilizado como principal parâmetro de qualidade da água e serve para determinar o impacto de poluentes sobre corpos hídricos.

Para Araújo et. al. (2004) o oxigênio é utilizado como principal parâmetro de qualidade da água e serve para determinar o impacto de poluentes sobre os corpos da água. É um importante fator no desenvolvimento de qualquer planejamento na gestão de recursos hídricos. O consumo de oxigênio é dado pela oxidação da matéria orgânica, respiração dos organismos aquáticos e demanda bentônica de oxigênio (sedimentos). Esse oxigênio é produzido pela reareação da atmosfera (difusão), na fotossíntese e pela entrada no mesmo em tributários e efluentes.

Preocupado com as implicações que o uso, ocupação e manejo da terra, estão impondo a qualidade das águas superficiais e de vida da população da bacia do córrego Bom Jardim, monitorou-se suas águas, no Verão e no Inverno de 2009, utilizando-se do oxigênio dissolvido e dos parâmetros coadjuvantes de turbidez, $\mathrm{pH}$ e condutividade elétrica, para 
avaliar sua qualidade e enquadrar a bacia nas classes do CONAMA, expressas pela Resolução 357/2005. E mensurar a eficiência da utilização do oxigênio dissolvido como principal indicador.

\section{Materiais e Métodos}

Para a mensuração dos parâmetros para a aferição da qualidade das águas superficiais do Córrego Bom Jardim, foram utilizados os equipamentos e métodos a baixo relacionados, no Quadro 01, que foram coletados no verão e inverno de 2009.

Quadro 01: Parâmetros, Equipamentos e Métodos Utilizado para Análise da Qualidade das Águas Superficiais do Córrego Bom Jardim, no Município de Brasilândia/MS

\begin{tabular}{|l|l|l|}
\hline Parâmetros & Equipamentos & Método \\
\hline Oxigênio Dissolvido OD & Lutron DO - 5510 & Espectrofotométrico \\
\hline Condutividade & Tecnopon MCA - 150 & Eletrométrico \\
\hline Turbidez & Tecnopon TB 1000 & Eletrométrico \\
\hline pH & Phtek pH - 100 & Eletrométrico \\
\hline Temperatura & Lutron DO -5510 & Eletrométrico \\
\hline
\end{tabular}

O oxigênio dissolvido é um gás solúvel em água, com concentrações recomendáveis pelo CONAMA Resolução 357 de 17/03/05, classe 1, de 10,0 a 6,0 mg/l $\mathrm{O}_{2}$ em qualquer amostra, Tabela 01 e Quadro 02. O método espectrofotométrico utilizado pelo equipamento Lutron DO 5510, será seguido para a verificação do oxigênio dissolvido. Segundo Araújo et al. (2004) o oxigênio dissolvido pode ser utilizado como indicador de qualidade das águas superficiais, pois a proliferação bacteriológica depende diretamente de suas concentrações, constituindo de metodologia de rápida análise, passível de realização no campo.

A condutividade expressa a capacidade de condução de corrente elétrica de sais dissolvidos e ionizados presentes numa água, pode ser utilizada como parâmetro de avaliação de qualidade. O método utilizado é o eletrométrico, segundo Matheus et al. (1995).

A turbidez é a alteração da penetração da luz provocada por partículas em suspensão, como bactérias, argilas e silte ou fontes de poluição que lançam materiais finos e outras substâncias na água. A presença dessas substâncias provoca a dispersão e a absorção da luz, dando à água aparência nebulosa, esteticamente indesejável e potencialmente perigosa (PINTO, 1998). Com concentrações recomendadas pelo CONAMA Resolução 357/05, classe I, até 40 unidades nefelométrica de turbidez NTU, Tabela 01 e Quadro 02.

$\mathrm{O} \mathbf{~ p H}$ apresenta a acidez ou a basicidade das águas, que podem ter origens em fatores naturais do terreno ou resultantes de poluentes dissolvidos na água. A analise do $\mathrm{pH}$ será feita através do método eletrométrico (CETESB, 1987). Para analise será utilizado os limites da Resolução CONAMA 357, de 17/03/05, que se estende de 6,0 a 9,0, Tabela 01 e Quadro 02.

A temperatura do ar e da água influencia nos processos biológicos, reações químicas e bioquímicas que ocorrem na água e também outros processos como solubilidade dos gases dissolvidos, além de acentuar a sensação de sabor e odor (PINTO, 1998). Para a análise da temperatura do ar e da água será utilizado o método eletrométrico (CETESB, 1987). 
Tabela 01: Limites dos Parâmetros Analisados para Enquadramento nas Classes das Águas Doces no Brasil

\begin{tabular}{|l|l|}
\hline Classes & Limites para o Enquadramento \\
\hline Especial & $\begin{array}{l}\text { Nas águas de classe especial deverão ser mantidas as } \\
\text { condições naturais do corpo de água. } \\
\text { OD }+10,0 \mathrm{mg} / 1 \\
\text { pH } 6,0 \text { a } 9,0 \\
\text { Turbidez até } 40 \mathrm{NTU}\end{array}$ \\
\hline I & $\begin{array}{l}\text { OD } 10 \text { a } 6 \mathrm{mg} / 1 \\
\text { pH } 6,0 \text { a } 9,0 \\
\text { Turbidez até } 40 \text { NTU }\end{array}$ \\
\hline II & $\begin{array}{l}\text { OD } 6 \text { a } 5 \mathrm{mg} / 1 \\
\text { pH } 6,0 \text { a } 9,0 \\
\text { Turbidez } 40 \text { até } 100 \mathrm{NTU}\end{array}$ \\
\hline III & $\begin{array}{l}\text { OD } 5 \text { a } 4 \mathrm{mg} / 1 \\
\text { pH } 6,0 \text { a } 9,0 \\
\text { Turbidez } 40 \text { até } 100 \mathrm{NTU}\end{array}$ \\
\hline IV & $\begin{array}{l}\text { OD }-4 \mathrm{mg} / 1 \\
\text { pH } 6,0 \text { a } 9,0 \\
\text { Turbidez acima de } 100 \mathrm{NTU}\end{array}$ \\
\hline
\end{tabular}

Fonte: Resolução n. 357 do CONAMA de 17/03/2005

Quadro 02: Classificação das águas doces brasileiras, segundo seus usos preponderantes, de acordo com a Resolução CONAMA n. 357/2005.

\begin{tabular}{|l|l|}
\hline Classes & Principais Usos \\
\hline Especial & $\begin{array}{l}\text { Consumo humano com desinfecção; Preservação de equilíbrio natural das } \\
\text { comunidades aquáticas; Preservação dos ambientes aquáticos em unidades de } \\
\text { conservação de proteção integral. }\end{array}$ \\
\hline I & $\begin{array}{l}\text { Consumo humano, após tratamento simplificado; Proteção das comunidades } \\
\text { aquáticas; Recreação de contato primário (natação, esqui aquático e } \\
\text { mergulho) Resolução CONAMA n. 274, de 2000; Irrigação de hortaliças que } \\
\text { são consumidas cruas e de frutas que se desenvolvam rentes ao solo e que } \\
\text { sejam ingeridas sem remoção de películas e à proteção das comunidades } \\
\text { aquáticas em Terras Indígenas. }\end{array}$ \\
\hline II & $\begin{array}{l}\text { Abastecimento para consumo humano, após tratamento convencional, à } \\
\text { proteção das comunidades aquáticas, à recreação de contato primário, tais } \\
\text { como natação, esqui aquático e mergulho, Resolução CONAMA n. 274, de } \\
\text { 2000, à irrigação de hortaliças, plantas frutíferas e de parques, jardins, campos } \\
\text { de esporte e lazer, com os quais o público possa vir a ter contato direto e à } \\
\text { aqüicultura e à atividade de pesca. }\end{array}$ \\
\hline III & $\begin{array}{l}\text { Abastecimento para consumo humano, após tratamento convencional ou } \\
\text { avançado, à irrigação de culturas arbóreas, cerealíferas e forrageiras, à pesca } \\
\text { amadora, à recreação de contato secundário e à dessedentação de animais. }\end{array}$ \\
\hline IV & \begin{tabular}{l} 
Navegação e à harmonia paisagística \\
\hline
\end{tabular}
\end{tabular}

Fonte: Resolução n. 357 do CONAMA de 17/03/2005 


\section{Resultados e Discussão}

Foram utilizados para análise de Qualidade das Águas do Córrego Bom Jardim os dados de pH, Oxigênio Dissolvido - OD, Condutividade, Turbidez e as temperaturas da água e do ar. (Tabelas 02 e 03 ).

As coletas das amostras de água foram efetuadas nas estações de verão e inverno de 2009, nos meses de março e setembro. As estações de coleta foram escolhidas previamente segundo critérios como: nascentes, foz, principais confluências, captação de água para consumo humano, descargas de efluentes e usos diferenciados do solo, dando ênfase à qualidade do canal principal (Figura 01). Com exceção da turbidez que foi mensurada em laboratório os demais parâmetros foram aferidos no campo.

A concentração de oxigênio dissolvido o principal indicador de qualidade aponta a estação 1 Inverno/2009, localizada próxima às nascentes do córrego Bom Jardim, como sendo a de menor valor de oxigênio $(7,1 \mathrm{mg} / \mathrm{l})$ devido à sua elevada vazão, relacionada às chuvas atípicas ocorridas nos dias que se antecederam as coletas na estação de Inverno. Registrando concentração baixa no Verão de 2009 na estação 6, com 8,6 mg/l, que pela resolução 357 do CONAMA de 2005, a enquadra na classe I. Os maiores valores foram obtidos respectivamente nas estações 2 , tanto na estação de verão quanto na estação de inverno, com 11,2 e $11,9 \mathrm{mg} / \mathrm{l}$.

$\mathrm{O}$ pH, como se pode analisar, devido sua ampla tolerância de 6,0 a 9,0, preconizada pelo CONAMA resolução 357/2005, estão todos as estações de amostragem dentro dos padrões, que o enquadram na classe especial. Bem com de potabilidade estabelecidos pela Portaria 1.469 do Ministério da Saúde de 2000.

A condutividade elétrica de modo geral é baixa, sendo mais elevada no Inverno/2009, sobressaindo à estação $6, \operatorname{com} 41,0$ um, a mais baixa foi registrada na estação $1 \operatorname{com} 4,81$ um no Verão/2009, no alto curso, em área de densa mata ciliar e campo de cerrado. Estima-se que o aumento da condutividade elétrica deu-se pelo carreamento de sólidos dissolvidos metálicos e de fezes animais e humanas, ricas em sódio. Pois a maior concentração deu-se no córrego Aviação que corta a cidade de Brasilândia e recebe boa parte de seus esgotos.

A turbidez de modo geral também é baixa, com exceção da estação 6 no verão que registrou 47,6 NTU, que enquadram-se pela resolução 357/05 na classe II, as demais estações posicionam-se na classe I.

Os dados dos parâmetros de Temperatura do Ar e da Água não foram aqui discutidos por não apresentarem relevância que alterasse os resultados finais da pesquisa.

Portanto a pesar das marcantes transformações na paisagem desse território verifica-se que o principal limitador de qualidade de uso da bacia é a turbidez e não o O.D. e a condutividade elétrica. Caracterizando, portanto grande diluição e assimilação promovida pela concentração das chuvas de verão, que ocorrem freqüentemente em Janeiro e Fevereiro, e o elevado transporte fluvial de sedimentos carreado das encostas suaves que comprometem a translucidez das águas da bacia. 


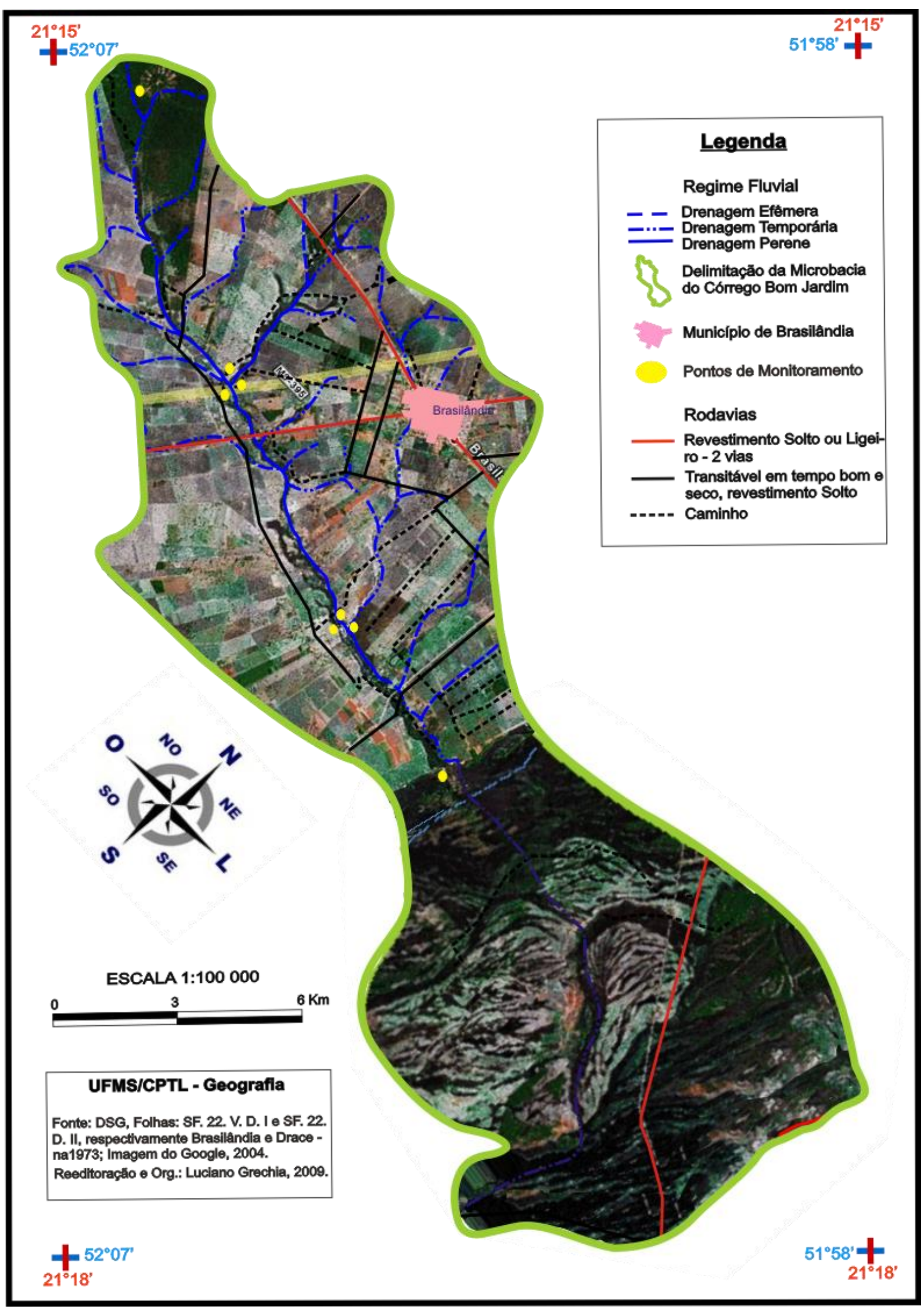

Figura 1- Mapa de localização das estações de coleta da Bacia do Córrego Bom Jardim em Brasilândia/MS. 
Tabela 02 - Parâmetros físico-químicos de Qualidade das Águas da Bacia, Verão/2009.

\begin{tabular}{|c|c|c|c|c|c|c|}
\hline Estações & $\begin{array}{c}\text { Condutividade } \\
(\mathbf{u m})\end{array}$ & $\begin{array}{c}\mathbf{O} \text {.D. } \\
(\mathbf{m g} / \mathbf{l})\end{array}$ & $\begin{array}{c}\mathbf{T}^{\mathbf{}} \mathbf{C} \\
\mathbf{A r}\end{array}$ & $\begin{array}{c}\mathbf{T}^{\mathbf{}} \mathbf{C} \\
\mathbf{H 2 O}\end{array}$ & $\mathbf{p H}$ & $\begin{array}{c}\text { Turbidez } \\
\text { NTU }\end{array}$ \\
\hline 1 & 4,81 & 10,20 & 29,10 & 26,4 & 6,90 & 6,78 \\
\hline 2 & 5,62 & 11,20 & 27,80 & 27,3 & 6,85 & 7,64 \\
\hline 3 & 5,76 & 10,10 & 32,00 & 27,2 & 6,81 & 8,86 \\
\hline 4 & 5,86 & 10,00 & 28,80 & 28,2 & 6,75 & 28,60 \\
\hline 5 & 6,66 & 10,40 & 32,50 & 28,5 & 6,65 & 8,71 \\
\hline 6 & 11,88 & 8,60 & 40,10 & 32,3 & 6,52 & 47,60 \\
\hline 7 & 6,88 & 9,10 & 32,20 & 28,4 & 6,61 & 11,40 \\
\hline 8 & 7,76 & 10,00 & 36,80 & 29,8 & 6,59 & 12,60 \\
\hline
\end{tabular}

Tabela 03 - Parâmetros físico-químicos de Qualidade das Águas da Bacia, Inverno/2009.

\begin{tabular}{|c|c|c|c|c|c|c|}
\hline Estações & $\begin{array}{c}\text { Condutividade } \\
(\mathbf{u m})\end{array}$ & $\begin{array}{c}\mathbf{O} \text {.D. } \\
(\mathbf{m g} / \mathbf{l})\end{array}$ & $\begin{array}{c}\mathbf{T}^{\mathbf{}} \mathbf{C} \\
\mathbf{A r}\end{array}$ & $\begin{array}{c}\mathbf{T}^{\mathbf{}} \mathbf{C} \\
\mathbf{H 2 O}\end{array}$ & $\mathbf{p H}$ & $\begin{array}{c}\text { Turbidez } \\
\text { NTU }\end{array}$ \\
\hline 1 & 21,00 & 7,10 & 24,80 & 24,10 & 7,00 & 8,00 \\
\hline 2 & 24,00 & 11,90 & 24,80 & 24,30 & 7,20 & 6,81 \\
\hline 3 & 21,00 & 7,30 & 24,10 & 23,40 & 7,60 & 16,20 \\
\hline 4 & 23,00 & 8,50 & 24,30 & 23,80 & 7,10 & 10,80 \\
\hline 5 & 27,00 & 7,20 & 26,90 & 24,30 & 7,00 & 7,51 \\
\hline 6 & 41,00 & 7,30 & 26,50 & 24,50 & 6,40 & 13,40 \\
\hline 7 & 30,00 & 8,20 & 26,40 & 24,40 & 6,80 & 8,87 \\
\hline 8 & 30,00 & 8,40 & 28,80 & 24,90 & 7,00 & 13,50 \\
\hline
\end{tabular}

\section{Conclusões}

A facilidade de obtenção das mensurações das concentrações de oxigênio dissolvido no campo, seu baixo custo e eficiência demonstram sua viabilidade para enquadramento nas classes de limitações de uso dos corpos hídricos lóticos do CONAMA, resolução 357/2005. Haja vista que, as campanhas efetuadas pelas secretarias municipais e estaduais, para avaliarem as condições dos cursos fluviais que cortam seus territórios são onerosos e por essa razão, não são realizados freqüentemente, com a redução dos custos, com a utilização do O.D. estes poderão ser efetuados com maior constância.

Conclui-se ainda, que a reduzida cobertura vegetal, em especial ciliar, a precária utilização de práticas conservacionistas empregadas no uso, ocupação e manejo da terra, produzidas pela ação antrópica associadas às fragilidades ambientais naturais de seus solos friáveis e pouco coesos, derivados do arenito Bauru, ricos em dióxido de ferro, apesar da baixa declividade, entre 0 a 3\%, influem na elevada competência fluvial de transportes de sedimentos e no consumo de OD. Que além de assoream o médio e baixo curso da bacia do Bom Jardim e de sua foz no rio Paraná, no lago da represa de Porto Primavera, compromete a qualidade de suas águas superficiais e de vida da população ribeirinha, incluído a cidade de Brasilândia cortada por seu afluente, da biodiversidade da Reserva do Patrimônio Particular Natural - RPPN da Cisalpina e da aldeia indígena Ofayé.

Tomando-se por base o O.D. como principal indicador de qualidade de água de forma geral as estações se enquadram na classe especial. $O$ afluente, pela margem esquerda $\mathrm{o}$ córrego Aviação, enquadrou-se na classe 1, impondo-lhe pequenas restrições de uso.

Contudo a população local utiliza-se se suas águas in natura, ou de captação por poços freáticos, fora dos padrões da Portaria 1.469 de 2000 do Ministério da Saúde. 
A falta de cumprimento da legislação quanto a praticas conservacionistas das reservas legais são os problemas centrais ocorrentes na bacia e que devem receber toda atenção no Plano Diretor e no Plano Diretor das Águas do município de Brasilândia. Sendo assim a necessária preservação e restauração das suas matas ciliares.

\section{Referências Bibliográficas}

ARAÙJO, S. C. de S.; SALLES, P. S. B. de A.; SAITO, C. H. Modelos qualitativos, baseados na dinâmica do oxigênio dissolvido, para avaliação da qualidade das águas em bacias hidrográficas. Desenvolvimento tecnológico e metodológico para medição entre usuários e comitês de bacia hidrográfica. Brasília: Departamento de Ecologia. Editora da UNB, 2004. p.9-24.

BRASIL Conselho Nacional do Meio Ambiente - CONAMA Resolução 357/2005, Enquadramento do Corpos Hídricos Superficiais no Brasil.. Governo Federal, Brasilia. Publicada no DOU n 53, de 18 de março de 2005, Seção 1, páginas 58-63.

CASSETI, V. Elementos de Geomorfologia. Goiânia: Editora de UFG, 1994.

CESP Plano de Manejo da Reserva Cisalpina. Companhia Energética de São Paulo: Relatório. São Paulo, 2007: 234p.

CETESB. Companhia de Tecnologia de Saneamento Básico. Guia de coleta e preservação de amostras de água. São Paulo, 1987: 150p. (Séries guias)

ESPÍNDOLA, E.L.G. et. al. - A Bacia Hidrográfica do Córrego Monjolinho. RIMA. USP -Escola de Engenharia de São Carlos. São Carlos, 2000.

MATHEUS, C. E. et.al. Manual de análises limnologias. BICRHEA - Centro de Recursos Hídricos e Ecologia Aplicada da USP. USP. São Carlos, 1995: 62p.

MINISTÉRIO DA SAUDE- Portaria N 1.469 Controle e Vigilância da Qualidade da Água para Consumo Humano e seu Padrão de Potabilidade. Brasília, Dezembro de 2000.

PINTO, A. L. Saneamento Básico e suas Implicações na Qualidade das Águas Subterrâneas da Cidade de Anastácio (MS). 1998. 175p. Tese (Doutorado e Geociências) - Universidade Estadual Paulista/Instituto de Geociências e Ciências Exatas, Rio Claro, 1998.

ROCHA, O; PIRES, J. S. R.; SANTOS, J.E. dos. A bacia hidrográfica como unidade de estudo e planejamento. In: A bacia hidrográfica do rio Monjolinho: Uma abordagem Ecossistêmica e a visão interdisciplinar. São Paulo: RIMA, 2000. p.1-16.

TUCHOBANOGLOUS, G.; SCHROEDER, E. D. Water quality - characteristics, modelling, modfication. Addison-Wesley Publ. Co., EUA, 1985. 